\title{
MODELO INTERACTIVO FUNCIONAL DEL SISTEMA DE TELEVISIÓN
}

\section{Cesar Augusto Ramirez Corzo*}

\author{
Fecha de recibido: 9 de octubre de 2011 \\ Fecha de aprobación: 15 de noviembre de 2011 \\ Artículo resultado de Investigación.
}

\begin{abstract}
Resumen
El siguiente artículo presenta el modelo comunicativo interactivo mediante el cual se describe, se analiza y se demuestra la incapacidad del sistema de televisión en Colombia para garantizar la protección de los menores de edad frente a los contenidos televisivos, destacándose tres subsistemas: el industrial, el humano y el legal. El modelo permite visualizar cómo funcionan y se integran los actores, cuáles son su propósitos, y el impacto que generan en el público receptor. El marco teórico se centra en el Interaccionismo Simbólico y en el estructural funcionalismo, para demostrar como el menor de edad queda totalmente expuesto a unos intereses económicos de la industria, sin suficiente protección del sistema legal, produciendo graves consecuencias en su dimensión espiritual, personal y social. El modelo comunicativo interactivo se convierte en un referente de análisis para investigaciones sociales que contemplen la influencia de los contenidos culturales en el individuo y en la sociedad.
\end{abstract}

\section{Palabras clave}

Símbolo significante, modelo interactivo, subsistema industrial, subsistema humano, subsistema legal, espíritu y persona

\section{FUNCTIONAL MODEL INTERACTIVE TELEVISION SYSTEM}

\begin{abstract}
This paper presents the interactive communication model whereby described, analyzed and demonstrated the inability of television in Colombia to ensure the protection of minors against the content of television, emphasizing three subsystems: industrial, human and legal. The model illustrates how the actors are integrated and what are their purposes, and the impact generated in the receiving public. The theoretical framework focuses on symbolic interactionism and structural functionalism, to show how under age is fully exposed to some economic interests of the industry without adequate protection of
\end{abstract}

\footnotetext{
Comunicador Social, Especialista en Mercadeo, Master en Estudios Políticos por la Universidad Javeriana, Doctor en Sociología Jurídica e Instituciones Políticas por la Universidad Externado de Colombia. Director y Presentador programas de Radio y Televisión, desde 1983 hasta la fecha (Abril 2011). Empresas: Radio Bucaramanga, Cadena Súper, Caracol Televisión, AMD Televisión, TEVECINE, UNITV, 88.9 SUPER STEREO, CM\& TV, PRODUCCIONES CARC, Entre otros medios. Corresponsal Internacional en Estados Unidos, Francia, México, Mónaco, entre otros países. Afiliado a la American Sociological Association, Broadcast Education Association, National Academy of Recording Arts and Sciences, Radio Television News Director Association, National Communication Association. Correo electrónico: carctv@yahoo.com.mx
} 
the legal system, causing serious consequences in its spiritual, personal and social. The interactive communication model becomes a benchmark of analysis for social research that considers the influence of cultural content on the individual and society.

\title{
Keywords
}

Significant symbol, interactive model, industrial subsystem, human subsystem, legal subsystem, spirit and person.

\section{MODELO FUNCIONAL SISTEMA DE TELEVISÃO INTERATIVA}

\begin{abstract}
Resumo
Este artigo apresenta o modelo de comunicação interativo através do qual descritos, analisados e demonstrou a incapacidade da televisão na Colômbia para garantir a protecção dos menores contra o conteúdo da televisão, enfatizando três subsistemas: industrial, humano e legal. O modelo ilustra como os atores são integrados e quais são seus propósitos, eo impacto gerado no público receptor. O referencial teórico centra-se em interacionismo simbólico e funcionalismo estrutural, para demonstrar como a criança está totalmente exposto a alguns interesses económicos da industria, sem proteção adequada do sistema legal, causando graves conseqüências em seu dimensão espiritual, pessoal e social. O modelo de comunicação interativa torna-se uma referência de análise para a investigação social que considerar a influência dos conteúdos culturais sobre o indivíduo ea sociedade.
\end{abstract}

\section{Palavras-chaves}

Símbolo significativo, o modelo interativo, o subsistema industrial, o subsistema humano, subsistema jurídico, espírito e pessoa.

"Si la televisión se usa para distraernos, engañarnos y aislarnos, entonces la televisión y aquellos que la financian, los que la ven y los que trabajan en ella, verán un panorama diferente muy tarde".

\section{Edward R. Murrow}

\section{INTRODUCCIÓN}

Se ha entendido, luego de muchas horas de trabajo y estudio, después de los diálogos con el grupo de consulta de 1.455 estudiantes, gracias al trabajo y soporte de personas expertas y a conversaciones en el marco de múltiples reuniones especializadas, congresos, foros, entre otras fuentes, que el menor de edad (en Colombia y el mundo) se encuentra indefenso, enfrentado a través de su aparato receptor (cualquiera que este sea: su televisor, su computador conectado a Internet, su iPod, su mp3, su mp4, su teléfono celular de última generación, su radio, etc.), con un sistema inmenso e infinito de posibilidades de información, imágenes y datos perfectamente organizados y trabajado para influir en su vida desde antes de evidenciar tal hecho.

Para efectos metodológicos y para el desarrollo teórico, se propone visualizar y abordar la investigación utilizando un modelo interactivo en el cual se han incorporado los actores seleccionados: industria, persona y sociedad, así como el marco legal. Estos tres subsistemas están 
inmersos en un entorno cultural, en un sistema social, en un marco de valores, influenciados por la ética, la moral, los mundos virtuales, entre otros elementos que inciden en este proceso interactivo.

La industria se presenta desde la perspectiva propia de sus intereses económicos, sus propósitos misionales y desde las estructuras definidas para su operación y transmisión de sus productos, ya sean contenidos televisivos o de consumo. Una vez aclarada la razón de existencia de las compañías de televisión, se aborda el proceso que realizan para transmitir sus mensajes y la forma como se contactan e interactúan con la persona y con la sociedad.

Se discuten las diferentes posibilidades de interacción en el modelo: industria-persona, industria-sociedad, persona-industria-persona, o persona-tecnología-persona, entre otras opciones de creación, distribución y recepción de contenidos televisivos.

Al utilizarse el modelo interactivo en los diferentes acápites de la investigación, se convierte en una herramienta útil para entender cómo funciona el gran sistema de la televisión, el impacto en la dimensión personal y social de los individuos y para comprender las nuevas dinámicas de la nueva era social que se discutirá.

De acuerdo con Parsons (1970; p. 162 y 163):

Concebimos a todo sistema formado por dos o más unidades o miembros interactuantes, y enclavado en una situación ambiental. Típicamente, cada unidad tiene contacto directo con algunas partes de la situación que constituye el ambiente en su conjunto, pero no son todas las partes. De igual modo, cada unidad tiene contacto directo con otras unidades, pero no necesariamente con todas. Puede decirse que el sistema en su conjunto cambia la relación que mantiene con su situación solo a través de la interacción de sus unidades entre sí y con entidades externas al sistema. Análogamente, se concibe que el sistema cambia su estado interno solo a través de la interacción de sus unidades.

Esa realidad se puede figurar en torno a un sistema que en la más clásica interpretación de Parsons, se compone hacia su interior de al menos dos unidades en interacción:

Si suponemos que para construir nuestras categorías debemos tener en cuenta, como mínimo lógico, siquiera dos unidades miembros, parece forzoso concluir que nuestro lapso habrá de involucrar al menos cuatro segmentos temporalmente distintos: 1) un segmento durante el cual se describe al sistema como una estructura latente, lista en potencia para funcionar de alguna manera; 2) un segmento durante el cual actúa una unidad miembro, 3) un segmento en el que reacciona la otra unidad miembro, $y$ 4) un segmento durante el cual se describe al sistema en términos de su estructura latente resultante, posiblemente con algunos cambios con respecto a su estado anterior" (p. 162)

Aplicando el referente de Parsons, por una parte está el subsistema industrial que representa la televisión y que recoge todos los elementos físicos y no físicos que componen la oferta disponible del sistema. Por la otra está la persona, quien tiene también en el medio social su propio subsistema de respaldo y como en el caso homólogo, genera lo que sería la demanda del sistema. Los dos sistemas entran en contacto e interacción a través de un elemento de punta. De parte del primero están los medios, que transmiten propaganda, entretención, diversión, mensajes, publicidad y demás, y son la vía de entrada a la persona por intermedio del aparato receptor. Este aparato receptor también es producto del trabajo del subsistema industrial que se mueve para ofrecer alternativas cada vez más sofisticadas. De parte del segundo está el individuo como persona, y 
en sentido genérico una persona de cualquier edad, que es el receptor y vía de entrada al subsistema social.

El modelo interactivo tiene el carácter de estructura, tal como lo define Levi-Strauss:

En primer lugar, una estructura ofrece un carácter de sistema. Consiste en elementos tales que una modificación cualquiera de uno de ellos entraña una modificación de todo lo demás. En segundo lugar, todo modelo pertenece a un grupo de transformaciones, cada uno de los cuales corresponde a un modelo de la misma familia, de modo que el conjunto de transformaciones constituye un grupo de modelos. En tercer lugar, las propiedades indicadas antes permiten prever cómo reaccionará el modelo en caso de modificación de uno de los elementos. Finalmente, el modelo debe ser construido de un modo tal que su funcionamiento pueda dar cuenta de todos los hechos observados. (Giner, S., Lamo, e., y Torres, c., 2002, p. 274)

Figura 3. Sistema Interactivo de Televisión

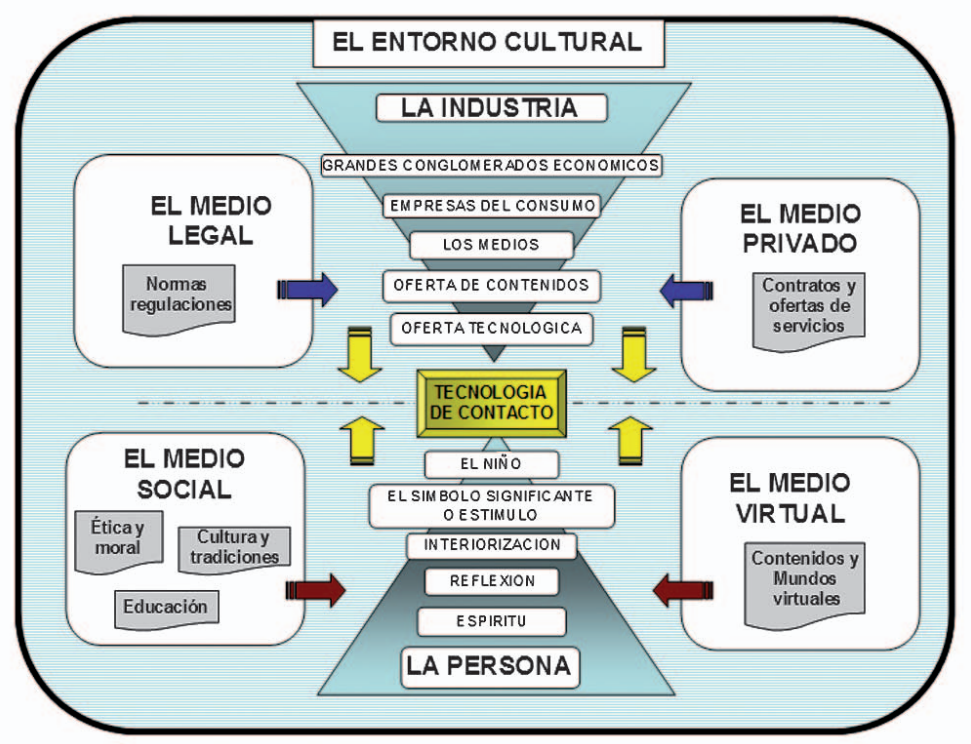

Fuente: Elaboración propia de acuerdo al análisis realizado por el autor.

Hay que dar al modelo un marco dentro de la sociología jurídica puesto que la televisión se proyecta como un fenómeno sociológico, el cual ha entrado en el "campo de investigación de los factores sociales que inciden en la organización, estructura, desarrollo y concepción del derecho y del estado" (Ibid. p. 733).

El problema sistémico estructural se presenta cuando comienzan a transitar productos e información de la industria a la persona, provocando una reacción en ella, de acuerdo con sus expectativas, preparación, educación y nivel de madurez. Si el televidente es un adulto, no hay mayor margen de preocupación en tanto ésta persona, cuando es razonablemente normal, es completamente responsable de sus actos; pero si fuese un menor de edad, que no tiene los niveles deseables de desarrollo y madurez, los problemas de impacto $y$ efecto se hacen evidentes enseguida.

El subsistema industrial tiene dos elementos importantes de soporte, que son: la legislación, en tanto norma que regula la prestación del servicio; 
y los contratos, es decir, los pactos comerciales que sostienen el esquema industrial y permiten el tránsito de sus intereses económicos.

El individuo por su parte, cuenta con otras personas para su proyección y tránsito hacia el constructo social y consigo mismo, para su viaje hacia los constructos virtuales. Con esos dos elementos, el uno real y el otro imaginario, la persona se enfrenta a la infinita gama de oportunidades informativas que le presenta el subsistema industrial, con el único soporte real que le da su propia fortaleza de espíritu. Esa interacción directa entre la persona y la industria puede realizarse de modo directo, incluso sin que el medio social participe en el hecho.

\section{EL SUBSISTEMA INDUSTRIAL}

¿Para qué existe una industria como la televisión, entendida como la transmisión a distancia de imágenes, sonido, símbolos y mensajes con un contenido predeterminado y casi siempre calculado? Es posible que no se tenga consciencia de la magnitud de este invento para la humanidad, y tal como expresa la sentencia de Murrow, que sirve para abrir este capítulo, pronunciada cincuenta años atrás, pero totalmente vigente en la actualidad: "es posible que se tome cuenta del hecho nocivo de la televisión cuando sea muy tarde" (Murrow, 1958).

Detrás de esa preocupación pueden surgir otras preguntas relacionadas, por ejemplo: ¿Qué objeto tiene la televisión? ¿A quién sirve? ¿De quién es la televisión? ¿Quiénes están detrás de ella? Son preguntas de enorme trascendencia porque tocan las entrañas de uno de los sistemas más poderosos e importantes de la cultura y de la civilización moderna. ¿Tiene sentido que exista la televisión? ¿Qué hace la industria para sostenerse? ¿Es la industria consciente de los efectos que causa? ¿Vale la pena preservarla como factor vital de la civilización actual?

La televisión es una de las herramientas sociales y culturales del mundo actual. Tiene una gran capacidad de penetración en la mente de las personas y con mayor poder, de influencia en sus conductas. Es un elemento cultural de valor indiscutible y para confirmarlo, basta pensar en el servicio que presta la televisión cuando cualquiera puede ver y enterarse instantáneamente de todo evento que suceda en el planeta, por intermedio de las cadenas noticiosas y disfrutar de forma simultánea de los mismos eventos con otros millones de personas. Gracias a ella, se puede estar (sin estar) y trasladarse (sin moverse) en cuestión de segundos de un lugar a otro, conocer casi todo el planeta sin necesidad de estar físicamente en cada lugar, pero sobre todo, poder llevar información a millones de personas al mismo tiempo y que ellas la reciban en la comodidad de su hogar. Ese es un valor que está fuera de toda discusión. La televisión es como una especie de premio, que se ha ganado la humanidad, en tanto se encuentra casi al alcance de toda persona en el planeta. Por eso hay pleno acuerdo con Murrow, en su apreciación del fenómeno comunicativo cuando afirma que la televisión es más que una caja de luces y cables y cuánto debe preocuparnos el uso que haga esta civilización de semejante invento ${ }^{1}$.

La industria de la televisión es ante todo un gran negocio. Los grandes conglomerados económicos, como se demuestra en la investigación, han adquirido y desarrollado productos mediáticos y de consumo, con una gran impacto a nivel mundial, convirtiendo el proceso de comunicación en un negocio de gigantescas proporciones. El punto de partida sugerido, para abordar el papel de la industria en el modelo, son sus intereses económicos y sus razones de poder para crear $\mathrm{o}$ adquirir las empresas televisivas.

Una vez definida su parte misional, la industria crea una plataforma de producción y de comercialización para poder llegar a sus receptores. Gracias a los nuevos desarrollos tecnológicos,

1 SHISTER, Gail. "The Incompatible Combination of Show Business, Advertising and News", 50 YEAR OF MURROW, RTNDA Communicator magazine, march, 2008, p. 16. 
esta conexión ha sido más sencilla, tanto para las empresas como para los consumidores, y de otra parte, se ha logrado un cubrimiento a escala planetaria, jamás imaginada. Hoy en día, cualquier canal puede llegar a millones de televidentes ya sea por plataformas de televisión, como con la utilización de Internet.

\subsection{Punto de contacto}

El sistema tiene una apariencia de pirámides, en las cuales y desde la base hasta el vértice, se acomodan en los distintos componentes de los dos subsistemas que integran el sistema: la industria y la persona, enfrentadas la una a la otra por sus vértices. Allí, en el vértice, haciendo la unión de los dos subsistemas, está el aparato receptor. Se designa también como tecnología de contacto. Hasta hace pocos años, no más de dos décadas quizás, el punto de contacto entre la industria y el individuo eran su radio y su televisor, y probablemente, pero en menor grado, las revistas y los medios impresos. Hoy la persona dispone de inmensidad de alternativas, comenzando por su computador y los equipos portátiles, que le ponen a su alcance la red mundial y las comunicaciones a un costo relativamente bajo.

Ese aparato receptor, producto de la que se vincula como industria paralela, con tecnología cada vez más sofisticada, con mayor funcionalidad, más económica, se convierte en la llave mágica para ingresar al mundo inconmensurable de la información y el entretenimiento, sin limitación alguna y 24 horas al día. El receptor es el vehículo, es el medio, a través del cual el individuo tiene oportunidad de entrar - sin barreras- al mundo infinito de la información y la diversión. Entonces hay que tener uno. No es concebible en la actualidad que la persona no disponga siquiera de un televisor, pero una vez superada esa meta querrá teléfono celular, y computador personal, y un iPod o cualquier otro dispositivo, porque tiene que ser así, como si fuese ésta, una condición que imponen los tiempos modernos para poder sobrevivir.

\subsection{Capitales e intereses}

En el primer nivel del subsistema están los propietarios, los capitales y los conglomerados que ejercen el poder e invierten grandes sumas de dinero en una industria en la que confían plenamente. Las inversiones mundiales en televisión son gigantescas y aumentan cada día. La industria sigue creciendo no por otra razón que la de ser promisoria y evidentemente rentable. Tómese nota de lo que sucede en Colombia con la perspectiva de un tercero y tal vez cuarto canal privado, que pretende seguir la ruta de RCN y CARACOL, y los incesantes movimientos en el mundo entero para acrecentar el poder de conglomerados como CNN, ABC, BBC, NBC, FOX, TBS, TELMEX, sin contar con lo que hacen los líderes de Internet como Google, Yahoo, Facebook, entre otras empresas, para entrar en el dominio de la televisión. Es tan llamativo este asunto de estar frente al sillón en cada hogar de los americanos, como dijera alguna vez David Sarnoff, Presidente de la tradicional RCA, que la televisión derivó sin atenuante en el sistema de transmisión vertical de mensajes comerciales y de entretenimiento que se conoce en la actualidad (Rodman, 2009, p. 283). El cine hizo lo mismo con éxito total: la incursión en el medio televisivo de compañías como Disney, Universal, MGM, HBO, Warner, Sony lo demuestran; y lo hizo a su vez la industria del entretenimiento: Playboy, MTV, HTV, para citar sólo algunos ejemplos. ¿Se hace todo este esfuerzo para entrar en algo que no vale la pena? ¿Se puede imaginar que haya gigantescas inversiones de capital en algo que no sea definitivamente un atractivo negocio?

La televisión es un atractivo real para la oferta de capitales y lo seguirá siendo en tanto exista la posibilidad cierta de que cada ser humano vea televisión, y por esa vía llegue a ser un comprador potencial de algún producto que puede anunciarse para millones de espectadores. Esa es una perspectiva comercial realmente grande y solamente hablando de la población del planeta que puede tener poder adquisitivo y está en disposición de viajar hasta los centros 
comerciales a adquirir lo que desea. Cuando los productos ya pueden ser adquiridos sin abandonar la comodidad del hogar, las proporciones de la operación comercial pueden llegar a ser muy grandes. Allí está el incentivo real para la fabulosa inversión de capitales en todos los países del mundo.

Cuando apareció la televisión por cable, y se abrió el mercado de los suscriptores, se vislumbró ésta como una posibilidad de desconcentrar el sistema, pero con extrema rapidez se asumió el control desde los grandes consorcios (Toffler, 1991, pp. 333 - 335), porque se sabía de qué tamaño sería el negocio. Se puede poner de presente el caso de Telmex, que tiene en su propietario Carlos Slim, uno de los hombres más ricos del mundo y que logró en menos de cinco años acaparar en Colombia las principales compañías de televisión por cable.

Ese es el primer nivel del sistema que se propone, el de las personas que con la visión y el interés que sea, forman parte de conglomerados de capital que están detrás de los medios (prensa, radio, televisión, Internet, etc.) y obviamente influyen en su desempeño. Tal es el poder que tiene la televisión, que incluso los gobiernos la tienen como un instrumento necesario para la tarea de gobierno (mucho más los gobiernos de facto), como lo ilustra Debray (1995, pp. 106 y ss), en la relación directa entre la industria cultural y la ley de la ganancia como instrumentos de dominación. Esa relación capitales-Estados es definitivamente lo más poderoso que existe. Como resultado de esa alianza, los gobiernos y los medios subsisten en perfecta simbiosis y se hacen parte integral del poder.

\subsection{Los canales de televisión}

No cuesta trabajo entender que las compañías sirven a los intereses de quienes las crean. Tratándose de los grandes grupos noticiosos, a los accionistas les interesa crecer en red y ejercer algún tipo de monopolio sobre la información y la noticia. Así lo han hecho y seguirán haciendo $\mathrm{CNN}$, FOX, NBC, y cualquier otra cadena noticiosa, como lo están desarrollando en Colombia los grupos españoles que han comprado a Caracol Radio y El Tiempo, y como puede estar sucediendo en cualquiera de las grandes economías del mundo.

A las compañías colombianas que están en televisión, les interesa mantener la concesión estatal del espectro electromagnético y posicionarse en el mercado como canal. Tomar posición en el mercado significa dominar en las franjas de tiempo y concentrar una jugosa pauta comercial. Para ello la fórmula no es otra que dominar las audiencias en horario triple A, sin descuidar por supuesto otros horarios que también son interesantes. El dominio de esta franja implica la plena vigencia del canal, pero especialmente la vigencia de su oferta: su mensaje. Esa es la perspectiva comercial que los canales nunca rehusarán. No pueden hacerlo porque es la pauta comercial, y la suscripción como segundo recurso, su principal fuente de ingresos. A menos que gozaran del beneficio de algún subsidio estatal, lo cual sería extraño, aunque de verdad no imposible, los canales han de centrarse en una exitosa operación comercial, para lo cual han de utilizar todos los recursos a su alcance para poder mantener cautiva la audiencia. Conquistar los receptores es un ejercicio en el cual, de acuerdo con Lindstrom, se emiten mensajes, imágenes y contenidos que el público objetivo no puede rehusar y no lo hace porque recibe por la televisión, el material que su cerebro le induce casi siempre de manera emocional (Lidstrom, 2008, pp. 23 y ss). Explica esto el por qué se exceden con tanta frecuencia en un tipo de programación, o de contenido, aparentemente en perjuicio de sus propios intereses. En realidad es totalmente al contrario, es en ese tiempo que la audiencia está cautiva e indefensa, es en el tiempo de reposo que el sistema inyecta toda la pauta comercial que les interesa para responder a sus abonados comerciales ${ }^{2}$.

2 Los monitoreos de IBOPE. muestran que $\mathrm{RCN} y$ CARACOL han llegado a emitir hasta 10 horas seguidas del mismo contenido: telenovelas. En esa banda de tiempo los productos más anunciados son justamente los de mayor consumo en el ambiente doméstico. Fuente informe semanal IBOPE, CM\& Televisión, noviembre de 2008. 
La constitución de un canal de televisión y su operación pueden ser costosas y probablemente la pauta comercial no sea suficiente, de tal suerte que será necesario el respaldo de grupos empresariales poderosos que orienten hacia allá sus recursos de inversión y la pauta comercial. El negocio de los canales, por lo tanto, es una operación de oportunidades múltiples en la que cuenta mucho la gestión comercial, sin embargo no es la única. Son también importantes las oportunidades en la pauta gubernamental, la cual suele ser grande y casi siempre ligada a lo que ha de conocerse como la distribución de poder. Las relaciones de poder, al lado de la lucha por la pauta comercial, se convierten entonces en la agenda diaria para las empresas y sus gerentes.

\subsection{La oferta de productos de consumo (la otra industria)}

Es importante notar que al lado de la industria de la televisión, la de la transmisión de contenidos, se desenvuelve otra que puede ser tanto o más poderosa, cual es la de la fabricación o manufactura de productos de consumo. Todo ello forma parte de la oferta comercial que tiene en la televisión su mejor (y a veces única) entrada al público en general. Como la gente ya no se toma el tiempo necesario para pensar y salir a buscar los productos que necesita, porque su trabajo, sus demás obligaciones, la velocidad y la falta de tiempo de la vida moderna no se lo permiten. La televisión hace ese trabajo de manera ejemplar. La industria del consumo se ocupa entonces de poner en la pantalla las cosas que las personas deben tener porque sí: la ropa de marca, los aparatos de última generación, los automóviles, los lujos y cosas superfluas, los electrodomésticos, la música, etc.

Todos productos, que la industria 'paralela' se esmera en innovar cada vez y en ofrecer para horizontes de tiempo cada vez más cortos. Basta preguntar a los jóvenes y jovencitas con cuánta frecuencia quieren cambiar su ropero, o su teléfono celular, o sus equipos portátiles, porque ya salieron al mercado los modelos nuevos y ello deja a los anteriores en estado de obsolescencia; o tal vez quienes quieren dejar de comprar los productos que desean, porque son de la marca que todo el mundo usa. Un estilo de vida costoso para la humanidad y el planeta, pero conveniente para la industria y para sus mejores aliados: el cine y la televisión. Los menores están expuestos a un ambiente de convergencia en el que disponen de varios equipos en su hogar. En cada hogar puede haber varios televisores, radios, consolas de video juegos, computadores, iPods, celulares, líneas de teléfonos locales, televisión abierta, satelital, por cable, Internet, etc. Es una realidad que se ajusta de modo explícito, a la figura que introduce el modelo de interacción y termina por confirmarlo.

\subsection{Los contenidos y los mensajes televisivos}

Queda la sociedad, y en particular los jóvenes tan proclives al cambio y a la novedad, expuestos a un mensaje que induce al consumo. Por una parte se ofrecen diversos artículos, productos comestibles, tecnología y en general miles de objetos, a lo cual sirve la excesiva pauta comercial que inunda la televisión. Y por otra parte están expuestos al material audiovisual, cargado de violencia, provocación al sexo, contenido erótico, lenguaje vulgar, mensaje indecente, mensaje exaltador negativo de la conducta, mensajes distorsionadores de los valores éticos y morales, como está registrado en los reportes especiales del Parents Televisión Council de los Estados Unidos $^{3}$. ¿Una televisión así, no tiene impacto en la sociedad y en las personas que la ven?

La respuesta está ya dada por la multiplicidad de estudios sobre televisión, que coinciden en señalar las graves consecuencias producidas en los televidentes, independientemente que no tengan la preparación necesaria para filtrar la información y procesarla adecuadamente. Para un menor de edad, en un país que solo ve telenovelas porque los canales a los cuales tiene acceso no emiten otra cosa, ¿qué clase de realidad se figura en su cabeza? Para otro menor de edad, al cual solo

3 Parents Television Council. Dying to entertain, Special Report, Los Angeles, January 2007, pp. 1 y ss. 
se le muestran televisión extranjera, ¿qué clase de identidad nacional y valores culturales se le puede pedir? Un escolar que solo ve televisión extranjera, (porque la televisión de su país solo emite telenovelas para adultos, que no son de su gusto y preferencia), puede terminar imaginando su vida fuera de la realidad que le corresponde.

El mensaje y contenido de la televisión consigue entonces, no solo el resultado de hacer de los menores de edad unos consumidores activos, también los homogeniza con respecto a cualquier otro individuo, de su misma edad en el planeta, que tenga acceso a las mismas plataformas. En efecto, un menor de edad colombiano que tiene un estándar de vida medio o alto, que accede por lo tanto a la televisión por suscripción, a Internet, tiene teléfono celular y baja música de la red para su equipo portátil, puede parecerse a cualquier otro niño del mundo que se encuentre en la misma circunstancia, en cuanto a su forma de ver las cosas, sus expectativas frente a la vida y las cosas que quisiera tener y hacer.

Ese es el efecto homogéneo que ha logrado la televisión, precisamente debido a su poder de penetración en la mente de los niños, niñas y adolescentes, quienes por carecer de preparación, por una parte, y por estar indefensos ante el asedio masivo del sistema, terminan influenciados en su conducta y expectativas frente a la vida y las posibilidades que ésta les ofrece. No es de extrañar que todos quieran ser modelos, cantantes, actrices y actores, o personajes famosos de la música y el deporte, porque ven en ello una ruta fácil, tal como se muestra en la pantalla, atractiva y llena de satisfacciones materiales. Susan Linn, profesora de la Universidad de Harvard, expresa que "los niños, incluidos, los más pequeños, regularmente ven televisión solos, lo que significa que ningún adulto está presente para ayudarles a procesar los mensajes" (2004, p. 5). Los menores están mirando la televisión aproximadamente 40 horas a la semana. El promedio de comerciales que reciben y ven por año es de 40.000. La mayoría de los programas para niños, inclusive hasta los canales públicos, tienen licencia para comercializar juguetes, ropa, y accesorios basados en los personajes y logos asociados con los programas (Ibídem). Eso convierte la televisión en una gran plataforma de mercadeo y el ejercicio de ver televisión, una visita forzada a los centros comerciales.

Uno de los fenómenos más preocupantes, observados en la televisión colombiana, en la actualidad, es la exagerada oferta de programas con contenidos referentes a mafia, narcotráfico, prostitución, corrupción, entre otros mensajes. El tema está generando una gran preocupación ante el altísimo nivel de aceptación de parte de los menores de edad. Las consecuencias de mostrar en los medios estos estilos de vida tan fascinantes y llenos de lujos, puede influir en los referentes sociales, con los cuales sueñan los menores de edad. No es de extrañar que, por su fragilidad, varios de ellos, deseen conquistar el mundo como mafiosos, delincuentes o criminales, porque lo aprenden de la televisión.

\section{EL SUBSISTEMA HUMANO: PERSONA Y SOCIEDAD}

Es necesario entender el concepto de sistema social, primero porque es conocido que la persona juega un papel importante en su composición y funcionamiento, y segundo porque, como ya se ha dicho desde el principio, la televisión forma parte de él. Siguiendo a Parsons, "Un sistema social reducido a los términos más simples - consiste, pues, en una pluralidad de actores individuales que interactúan entre sí en una situación que tiene, al menos, un aspecto físico o de medio ambiente, actores motivados por una tendencia a 'obtener un óptimo de gratificación' y cuyas relaciones con sus situaciones - incluyendo a los demás actores - están mediados y definidos por un sistema de símbolos culturalmente estructurados y compartidos" (2007, p. 17). Esta definición es la base que ilustra el concepto en el modelo interactivo propuesto.

A propósito del sistema social de la televisión, se agrega que "... un sistema social es sólo uno de los tres aspectos de la estructuración de un 
sistema total concreto de acción social. Los otros dos aspectos son los sistemas de la personalidad de los actores individuales y el sistema cultural que establece en sus acciones [...] Cada uno es indispensable para los otros dos, en el sentido que sin personalidades y sin cultura no existiría ningún sistema social" (Ibídem).

El concepto de estructura social implica que los contextos sociales de nuestras vidas no consisten en tomar las acciones de los eventos al azar. Estos son estructurados, o corresponden a patrones en distintas formas. El sociólogo Anthony Giddens (2009), expresa que existen regularidades en las formas como nos comportamos en las relaciones que tenemos con los otros. Las estructuras sociales no son como las estructuras físicas, como un edificio, que existe independientemente de las acciones humanas. Las sociedades están siempre en proceso de estructuración. Ellas están reconstruidas en cada momento por los bloques de construcción que las componen - seres humanos como usted y yo-. (Giddens, 2009. p.9)

El funcionamiento de la sociedad es un tema que ha ocupado a los pensadores de la humanidad desde los tiempos de la antigüedad hasta hoy. A juzgar por los nuevos desarrollos del pensamiento social, el funcionamiento de la sociedad es algo aún no resuelto en su totalidad. Detrás de esa pregunta ¿̇cómo funciona? hay de nuevo preguntas relacionadas: ¿Qué es lo que finalmente determina la dinámica social? ¿Cómo se regula la sociedad en sus procesos? ¿Tiene la sociedad control de sus propios procesos? ¿Debería tenerlos? ¿Hacia dónde se dirige la sociedad? Son preguntas que ponen en cuestión los fundamentos de la civilización misma. Se puede preguntar entonces, ¿tiene la sociedad control de la televisión, que es su arma cultural más importante? ¿Hay justificación para que siga adelante su proceso de modernización, si la sociedad ignora incluso el gigantesco instrumento de formación de cultura que tiene entre manos? ¿Se hará como sociedad algo al respecto, o cumplirá el simple papel de espectador del proceso? Las respuestas pueden ser tanto sencillas como complejas. La sociedad no puede darse el lujo (bastante cuestionable por cierto) de dejar la televisión, como cheque en blanco, en manos de la industria exclusivamente, sabiendo lo que pretende en materia de comercialización de productos y dominación de mercados y la evidente expansión en líneas de negocios que incluyen canales de televisión, estaciones de radio, proveedores de Internet, parques temáticos, compañías de música, editoriales, así como empresas de comidas, juguetes, ropa, y accesorios, entre una infinidad de productos. En virtud de este proceso un pequeño grupo de multinacionales controlan lo que los niños comen, beben, visten y juegan cada día.

La responsabilidad de la sociedad en este asunto está, por tanto, fuera de toda discusión. La televisión es una gran herramienta, de amplio alcance y cobertura, disponible para todos y la que tiene la capacidad de llevar los mensajes hasta la interioridad de todos los hogares. ¿Puede admitirse que la televisión quede en manos de industriales comprometidos con el mercado y no con la cultura? Se resalta la actitud de Francia, China, Australia y Canadá, o la de tantos otros países convencidos de su valor como sociedad y comprometidos en el cultivo de su identidad, su cultura y la protección de sus generaciones más jóvenes, que alegando razones de Estado los unos y de protección cultural los otros, han establecido restricciones para la televisión abierta y cuotas obligatorias de televisión cultural, televisión educativa, televisión infantil y han tomado medidas para promover y fomentar la producción nacional, tanto en cine como en televisión. Murrow (2008) expresó al respecto:

"Our history will be what we make it. And if there are any historians about fifty or a hundred years from now, and there should be preserved the kinescopes for one week of all three networks, they will there find recorded in black and white, or color (sic), evidence of decadence, escapism and insulation from the realities of the world in which we live"4.

4 MURROW, Edward R. En "Our History Will Be What We Make It", En 50 YEARS OF MURROW, RTNDA, Communicator magazine, march 2008, p. 15. 
Es una advertencia clara e inequívoca sobre el peligro que representa la televisión, el grave peligro de perder identidad, el grave riesgo de no hacer nada, y por lo tanto, la escalofriante disyuntiva de pagar las consecuencias de esa omisión tarde o temprano.

\section{¿Cómo opera el subsistema humano en el modelo?}

Desde el vértice hasta la base, el subsistema de la persona va agregando niveles de desarrollo y complejidad, comenzando en lo personal (esfera del yo individual) y terminando en la persona que surge luego de complejos procesos de internación de experiencias con los otros; en el más sencillo ejercicio de lo social, la reflexión y la interacción con la sociedad, como expresión del interaccionismo que ha sido tomado de Mead y Blumer entre otros destacados sociólogos. El subsistema tiene sus componentes montados justo en el orden que les corresponde dentro de la secuencia de maduración de la persona. El menor de edad, entra en contacto con los medios a través de su propio 'Yo' y de nadie más, por eso es tan importante entender que en este juego es el individuo quien se encuentra completamente solo $e$ indefenso, frente al descomunal sistema de la industria de televisión. Hay un aprovechamiento de su debilidad, o por lo menos, la actitud positiva hacia el mensaje, según lo definen Lakhani (2008) en el terreno de la persuasión subliminal y manteniendo ciertos secretos de su accionar frente al público televidente (pp. 2 y ss), para convertirlo sin que éste se percate de nada, y actuando sobre su sistema cerebral, en el primer consumidor de todo lo que se ofrece en el infinito universo de los productos de consumo (Lidstrom, pp. 24 y 25).

Esta es una realidad que cuesta aceptar pero está allí y ahora. No hay que ser expertos para sentirla, ni demasiado ingenuos para no reconocerla. El punto es que, una vez se ha tomado conciencia del hecho, hay que decidir qué hacer.

\section{EL INDIVIDUO PRODUCTOR Y CONSUMIDOR}

El individuo corriente ya puede participar en la creación de los contenidos de televisión. Este fenómeno ya se observa en los grandes canales de televisión, que han abierto franjas de programación para permitir a sus televidentes el envío de reportes, ya sean fotos, videos, comentarios, mensajes de texto, entre otros formatos. Dicho de manera simple, la industria tiene las plataformas tecnológicas y los receptores aportan contenidos.

De otra parte está el individuo, quien gracias a los desarrollos tecnológicos y a la oferta de dispositivos sencillos y de bajo costo, es capaz de crear sus propios contenidos. Los puede emitir a bajos costos en Internet, gracias a herramientas como You Tube, Google, los correos electrónicos, Facebook, My Space, Twittery cientos de opciones disponibles. Con estos recursos se multiplican las alternativas prácticas para el tránsito sencillo de imágenes e información. El individuo comienza a cumplir las mismas funciones del sistema industrial tradicional: crear contenidos y emitirlos para el público en general.

También está el individuo que utiliza sus propias plataformas y produce sus contenidos, pero en vez de enviar la información y contenidos a otros actores, los usa para sí mismo, creando un entorno virtual al cual sólo él tiene acceso. Este ambiente privado de los mundos virtuales, permite que los individuos participen, no sólo del contenido que ellos mismos capturan en las fuentes inagotables del ciberespacio, sino de otros materiales que círculos restringidos de personas comparten en el sistema. El mayor ejemplo de este sistema virtual está en herramientas como Second Life, entre otros casos. En estos mundos virtuales los usuarios construyen la realidad que desean: desde concebir y crear su propio hogar, armar grupos de juego, crear círculos de amigos, comunidades temáticas, y compartir todo lo que quieran producir. Están en los dos lados del sistema interactivo. De un lado producen y 
ensamblan sus propios contenidos y por el otro lado los consumen ellos mismos.

La persona se desarrolla a partir de la efectiva aplicación del lenguaje como factor de comunicación e interacción social. La persona, en consecuencia, evoluciona, se desarrolla con la práctica y la experiencia de las actividades sociales, es decir, es un resultado de tales relaciones. La persona tiene, por lo tanto, características definidas. A partir de tales, la persona se hace un objeto para sí, y esa característica le distingue de todo lo demás. La persona es por lo tanto una estructura social, surge en la experiencia social, se proporciona a sí misma sus experiencias sociales, y posteriormente las comunica a otros.

\subsection{La familia, sistema de soporte}

El individuo que madura comienza a tener progresivas conversaciones significantes con otras personas. Aquí se entiende, de nuevo con Mead, que por intermedio de la comunicación gestual hay un efecto en el individuo y que tal efecto es parte de aquello entendido como la conversación inteligente con otros. Es entonces la conducta social capaz de proporcionar la circunstancia dentro de la cual aparece la persona (Mead, 1999, p0. 172 y ss). Esa primera conducta social sucede en el seno de la familia, desde donde se espera que el individuo internalice la mayor parte de los aprendizajes básicos, para llevar adelante su vida social. La familia es un sistema de soporte para los procesos tempranos de formación, y es en ella donde el individuo realiza sus primeras aproximaciones a lo social. De allí ha de sacar los elementos básicos, para lograr una estructura completa que responda a las exigencias del proceso social como un todo, es decir, para poder llevar en adelante una vida social. En la familia las cosas comienzan a tener significación. Los símbolos, que son la base de la comunicación, comienzan a hacerse universales. La persona menor de edad se convierte en un miembro del grupo social más próximo. Sus gestos y conversaciones provocan reacciones en los demás, y desde allí se derivan principios de conducta que le identifican con su contexto o le diferencian de otros. El individuo reacciona a ciertos estímulos (a muchos la verdad) pero es inicialmente una persona incompleta, por eso hace una demanda permanente de apoyo que debe venir de su familia y del círculo social más inmediato (Ibíd., pp. 176 a 182).

La infancia y la adolescencia son períodos sensibles de la vida, en tanto se consolida en ella la necesidad de pertenecer, o sentirse relacionado, lo cual es indispensable para el desarrollo normal. Esa relación le convierte en un miembro consciente de sí mismo y de la comunidad familiar a la que pertenece (Ibíd., p. 189). El menor de edad quien hace parte de una familia puede tener por lo tanto, numerosas defensas en sus procesos de formación, no así aquel que carece de ella. Funciona en todo el reino animal. Se necesita de su aporte para la consolidación de una moral y de un conjunto de conductas que evidencian su forma de ser, todo en el marco de la interacción propia de todos los grupos sociales. ¿Qué pasa cuando la familia, aún sin estar rota o formalmente disuelta, no cumple ese papel? El menor de edad busca casi siempre otros referentes con los cuales pueda sentirse cómodo para expresar situaciones sociales en las que puede intervenir y que pueden tener para él mayor atractivo, tal vez más que aquel que puede ofrecer la propia familia, a la cual pertenece, o la comunidad en la que vive.

Se deja explícita la preocupación tanto en medio del análisis sociológico, como en el debate del entorno mediático, al decir que la familia juega también un papel orientador y formador en la estructura del individuo, particularmente cuando está dentro de sus responsabilidades, la de vigilar el buen ejercicio de ver televisión y asegurar para el niño, la niña y el adolescente las mejores oportunidades para su formación personal. Si la familia no cumple ese papel, y al contrario induce al menor a contenidos y mensajes que no son los adecuados para su edad, comienza a quedar claro el origen de las complicaciones de hoy, tan autorizadamente expuestas por los investigadores que acompañan este estudio. $\mathrm{El}$ 
problema cuando esto ocurre es que el espacio que deja libre el referente familiar o de los mayores lo ocupa la televisión y otros medios. A partir de allí la fuente mediática se convierte en el principal proveedor de símbolos, ejemplos y referentes de vida que el joven televidente toma sin mayores consideraciones para la construcción de su propio 'Mí'. Por esa razón se dice, y así se demuestra, que la televisión siempre ha estado en posición de trasformar la vida de los menores de edad ante la mirada impávida de sus familias y los mayores.

\subsection{La interacción social}

Mead sostiene que fuera de la familia, y casi siempre a despecho de ella, puede desarrollarse una organización más compleja que aquella de la cual ha surgido la persona, y que las personas suelen ser los órganos o las partes esenciales al menos, de esa organización social más elaborada dentro de la cual surgen e interaccionan las personas. Así comienza un proceso social detrás del cual tienen lugar las diferenciaciones propias de las personas y los grupos sociales. La persona adquiere una estructura que le distingue en la conducta social, y replica conductas que ha observado en su grupo social o comunidad. Con ello se está dando a entender que toda la comunidad actúa y ejerce influencia hacia el individuo, en determinadas circunstancias, $y$ siempre lo hace de la misma forma, de suerte que produce la relación que identifica tanto a los individuos como a toda la comunidad (Ibíd., p. 193), quedando de esta manera, cada uno por su propio lado, al hablar del factor cultural y la identidad de conducta entre las personas que se desarrollan en el mismo entorno (Rapaille, pp. 55 a 90). Estos elementos reciben el nombre de medio social en la caracterización del modelo interactivo.

\subsection{El entorno cultural}

En este contexto se llega al corazón del debate, a la sociedad como el ente que crea universales a partir de lo que ve y acepta de manera más repetitiva y normalizada. Debe caracterizar la conducta de las personas, esos rasgos culturales que han sido heredados y trasmitidos, insumo de los tiempos modernos no provenientes de la relación directa entre las personas, o la interacción comunicativa, cada vez más escasa, sino de la televisión. Si bien el individuo no necesita adoptar las actitudes de los otros, puesto que no son obligatorias, la televisión ha logrado convencerle en hacerlo, al presentarle paradigmas y referentes difíciles de ignorar. El individuo recibe hoy por la vía de los medios, más símbolos y mensajes que promueven cambios en su conducta. Una conducta orientada hacia lo universal, en la medida como aumentan las oportunidades mediáticas.

\subsection{El medio virtual}

La persona, de tal modo descrita y condicionada en su acción, es el sujeto entrando en contacto con el gran sistema de la televisión y la industria del entretenimiento. Es el sujeto moviéndose y viviendo en su propio ambiente de realidades virtuales (compartiendo el ciberespacio e inmersos en conceptos como la cibernética ${ }^{5}$ ) y lo hace en la plena soledad de su persona humana. Sartori (2005) lo expresa de modo original: " $E l$ nuevo soberano es ahora el ordenador, porque el ordenador (y con él la digitalización de todos los medios) no sólo unifica la palabra, el sonido y las imágenes, sino que además introduce al sujeto en las 'visibles' realidades simuladas, realidades virtuales" (p. 40).

No hay quien pueda ayudarle y orientarle en ese tránsito; solo el propio individuo, con sus recursos espirituales, entra en ese universo para

5 "El término cibernética fue acuñado por Norbert Wiener para denominar el 'control y la comunicación en el animal y en la máquina' (es el título de su libro en 1948). Esencialmente, la cibernética de Wiener trata de los 'mensajes de órdenes' que el hombre da a la máquina, pero también los que la máquina da a la máquina y los que ésta le devuelve al hombre. El significado etimológico de cibernética es 'arte del piloto'; pero los pilotos en cuestión son ahora los circuitos de órdenes y de control en las máquinas electrónicas." En SARTORI, Giovanni. Homo videns: La sociedad teledirigida, Punto de Lectura, Madrid, 2005, p. 39. 
tomar de allí lo que pueda satisfacer su curiosidad y sus ansias de aprender. Si el sistema le educa, le ofrece información y contenidos cada vez mejores y necesarios para sus procesos de formación, es perfecto: queda resuelto de paso el problema de los deficientes niveles de formación del sistema educativo convencional. Si al contrario el sistema le distrae de sus verdaderos objetivos y valores, le dispersa, le desorienta, le confunde, le genera falsas expectativas y le presenta falsas realidades, entonces es malo: se agravan de paso las obligaciones y exigencias para un nuevo esquema educativo que proyecte a los maestros y los escolares en las dimensiones reales de la nueva era digital, la del ciberespacio, la de la comunicación mediada. Los menores de edad ven televisión y hacen uso convergente de los medios, como también sucedería en los científicos del espacio, pueden experimentar un efecto de curiosidad, despertando su imaginación y su deseo de investigar y aprender, pero para ello se requiere de preparación y asistencia del maestro y de los padres para aprovechar debidamente el material. De lo contrario, como también puede pasar con los científicos en la comparación que se sugiere, pueden sobrevenir graves problemas de desorientación. Sartori agrega:

“...es la televisión la que modifica primero, $y$ fundamentalmente, la naturaleza misma de la comunicación, pues traslada del contexto de la palabra (impresa o radiotransmitida) al contexto de la imagen. La diferencia es radical. La palabra es un 'símbolo' que se resuelve en lo que significa, en lo que nos hace entender. Yentendemos la palabra sólo si podemos, es decir, si conocemos la lengua a la que pertenece; en caso contrario, es letra muerta, un signo o un sonido cualquiera. Por el contrario, la imagen es pura y simple representación visual. La imagen se ve y eso es suficiente, y para verla basta con poseer el sentido de la vista, basta con no ser ciegos. La imagen no se ve en chino, árabe o inglés; como ya he dicho, se ve y es suficiente" (Ibíd., pp. 41 a 42).

Por tal razón, la televisión es un hecho universal y el individuo que ve televisión es esencialmente idéntico a cualquier otro en el mundo; es de esperar que los efectos producidos en él sean los mismos que sufre un niño árabe, o un chino, o un ruso, cuando ven una propaganda de Coca-Cola, o de Disney, o de McDonald's, o algo por el estilo.

Ese justamente es el sujeto que preocupa, aquella persona que se enfrenta indefensa y no preparada a la inmensa cantidad de datos e imágenes que ofrece el ciberespacio y que 'entran' en su cerebro a través de los medios.

\section{EL SUBSISTEMA LEGAL}

Entendidos los subsistemas industria y sociedad, se presenta en el modelo Interactivo el subsistema legal. En el caso de la tesis se considera todo el aparato legal y regulatorio, que involucra las instituciones, los poderes ejecutivo, legislativo, judicial; las leyes, las regulaciones, los acuerdos, tratados internacionales y en general todo el aparato sistémico legal que permite la operación y funcionamiento de la industria de la televisión. Para efectos del estudio comparativo que se hace en el capítulo de ley, el modelo interactivo facilita la metodología para analizar todos sus actores y cómo opera en Colombia y en los referentes internacionales.

Se puede -dijo Mead (1999)- reformar el orden de las cosas o insistir en hacer que las normas de la comunidad sean mejores, pueden elevarlas a la categoría de ley, si es que esa es la representación de máximas garantías de restitución. Sin embargo, no hay obligación con ninguna norma o ley, más bien con la elevación de los principios que permiten hacer tranquilas las relaciones entre todos al interior de la sociedad (Mead, 1999, p. 196). Es cierto que el pensamiento, mientras no es más que pensamiento, es accesible sólo al organismo interior, o sea al propio 'Yo'. El carácter común del pensamiento, se logra en la medida en que se manifiesta en la acción. Dicho desde otra perspectiva, para dar lugar al proceso de pensamiento se requiere de la internalización de los mensajes significantes provenientes de la sociedad, mientras esta por su lado toma lo que interesa de cada individuo, no para hacer 
pensamiento o reflexión, -que no es su tarea- sino para crear universales, o para dar pasos hacia la institucionalización. Ese es el camino hacia la conformación de la norma y de la ley.

La conducta repetida o en términos de Mead, las series de reacciones comunes de la sociedad hacia una situación común, son la base formadora de instituciones (Ibíd., p. 278). Las instituciones se hacen universales solo en cuanto son reconocidas por todos: "Así, las instituciones de la sociedad son formas organizadas de actividad social o de grupo, formas organizadas de modo que los miembros individuales de la sociedad puedan actuar adecuada y socialmente adoptando las actitudes de los otros hacia dichas actividades" (Ibíd., p. 279). En ese marco se mueve la vida de las personas y de la comunidad como agregado de la vida de éstas. Allí, por consiguiente, se mueve el sistema de interacción entre el mundo de la industria, regulado por las normas y los contratos, y el mundo de las personas, regulado por la cultura y los constructos sociales.

\section{LA INFLUENCIA DE LA ÉTICA Y LA MORAL}

La ética y la moral, son paradigmas de la sociedad y de la humanidad, pero no logran ser propiamente un referente de los tiempos modernos. Pareciera como si en los actuales momentos, pocas son las cosas que se hacen en arreglo a ellas, y es así en el marco sistémico y funcional de la televisión. La norma imperante es la ética de los negocios y la moral se deja fuera de toda actuación.

En el medio social, por el contrario, "la referencia moral no es un absoluto exclusivo, pero sin la referencia social no es posible concebir un sistema de acción concreto como integrado en un sentido total. A causa de esta relevancia especial para el sistema social, los criterios morales llegan a ser el aspecto de la orientación de valor que tiene mayor importancia directa para el sociólogo" (Parsons, 2007, p. 24). Por eso se asume la ética y la moral como paradigmas obligatorios al lado de la educación. Los tres serían buenos ejes de la vida en sociedad, imprescindibles quizá para mantener el orden y el equilibrio dentro de la misma, especialmente para proyectar mejores seres humanos. ¿Funciona? No hay seguridad en ello. La ética y la moral parecen estar olvidados, y sin embargo deben ser referentes obligatorios al momento de contribuir en la construcción de la persona y la consolidación de sus propios modelos de conducta.

Si el subsistema de la televisión, como se sabe, no aporta mucho en ese terreno, corresponde a la sociedad hacer el esfuerzo necesario para cambiar la tendencia y lograr que las personas puedan formarse en equilibrio y mantengan los principios éticos y morales por encima de los intereses comerciales y de negocio. No por otra razón han sido colocados al lado de la educación. El sistema educacional, por consiguiente, quedaría con la responsabilidad de ensamblar estos dos elementos insustituibles en los procesos de formación de las personas. ¿La televisión debe ayudar en ello? Definitivamente sí, sin embargo es necesario aclarar que ante la circunstancia ya explicada, la televisión puede mostrarse libre de ese compromiso, y será siempre necesario avanzar en los terrenos de la negociación y del consenso para lograr verdaderos avances.

Con todos los subsistemas y actores así descritos en el marco de lo que se figura como el modelo interactivo del sistema de televisión, se da paso al debate en los tres ambientes o dimensiones principales: la televisión, mejor entendida como industria de la televisión, para ser más universales en el concepto; la ley, mejor entendida como el entorno legal e institucional que regula la televisión; y la persona y sociedad, como los actores que deben ser protegidos frente al impacto de los medios de comunicación. El modelo propuesto ayuda a entender teóricamente y metodológicamente el funcionamiento del sistema y el impacto que se genera en los menores de edad.

\section{CONCLUSIONES}

La reflexión planteada, es la urgente e imperiosa necesidad de encontrar caminos para proteger a 
los menores de edad, de los contenidos negativos que reciben de la televisión y de los medios de comunicación. Se demuestra la incapacidad del sistema para hacerlo. La industria, la legislación y regulación vigentes, los poderes y autoridades, los organismos de control de la televisión y lamentablemente la misma sociedad en Colombia, no han asumido la responsabilidad de actuar para evitar el daño producido por los contenidos a los cuales están expuestos los millones de menores de edad en el país.

Los intereses comerciales dominan la industria de la televisión, seguida de una incapacidad del sistema legal para evitar que los menores de edad sean impactados por tantos programas que les están afectando en todas sus dimensiones, ante la complacencia de un sistema político al cual no le interesa enfrentar el problema para no entrar en conflicto con los intereses comerciales de los conglomerados económicos, en su gran mayoría propietarios de los más importantes medios de comunicación. Las consecuencias negativas se presentan en la actitud y conductas de los menores de edad, produciendo trastornos en su construcción personal y social, impactando por supuesto en la identidad cultural, en la forma de pensar y proceder, en los paradigmas sociales, en las estructuras familiares, en el entorno social $y$ en muchas expresiones de la vida diaria.

Se advierte que los niños no son adultos. Ellos son seres frágiles, indefensos, inmaduros, y como seres en formación son altamente sensibles ante los contenidos mediáticos a los cuales se exponen. Lamentablemente, para la industria de la televisión los menores de edad se convirtieron en grandes compradores y consumidores de sus productos. Los grandes conglomerados económicos convirtieron en objetivos de mercado a millones de niños, niñas y jóvenes, quienes conectados a través de campañas de mercadeo y utilizando las más avanzadas técnicas de neuromarketing, adquieren los miles de productos que se les ofrece, logrando no sólo que los compren sino que se conviertan además en consumidores habituales. Este gran negocio permite a las empresas obtener millonarias ganancias en todo el planeta.
El objetivo es conquistar las grandes audiencias y lograr ventas millonarias de productos. La educación, la cultura, la protección de los menores, el refuerzo de la identidad cultural, entre otros aspectos aparentemente protegidos por la ley y la regulación, no tienen ninguna prioridad, quedando anulados casi por completo frente al gran negocio de la televisión.

Se advierte la pérdida de la identidad cultural de los menores de edad, quienes por múltiples razones de orden práctico declaradas por ellos en las entrevistas y en el sondeo, se han desplazado de la televisión nacional hacia la televisión extranjera, exponiéndose a contenidos televisivos con altas dosis de sexo, violencia, lenguaje vulgar $e$ inducción al consumo.

No se puede ubicar el problema sólo en alguno de los actores vinculados en el modelo interactivo. Debe tomarse el problema como un todo integral, que permita tomar control del sistema y en esa medida asegurar el servicio de televisión a unos y otros: al Estado para los fines de interés público, sugerido aquí como la cultura, la identidad nacional, la educación, la salud pública; para la industria, porque tiene derecho a que su negocio siga siendo bueno y promisorio, siempre y cuando no termine por afectar la sociedad; y a la sociedad, porque tiene la obligación de exigir televisión de calidad para su propio beneficio y sostenibilidad.

Las redes de la comunicación se expanden tanto que muchas veces las barreras de legislación o regulación, los nobles objetivos periodísticos, la responsabilidad social, los objetivos educativos y culturales, la corresponsabilidad y en general el mismo modelo interactivo propuesto en el trabajo como mapa conceptual, son insuficientes para poner en cintura un fenómeno que trasciende fronteras, sociedades, y tiene que enfrentar muchas barreras.

Se concluye este trabajo, referenciando a uno de los investigadores más comprometidos con el tema de la protección de los niños, niñas y adolescentes. Neil Postman (1994) advirtió hace varios años 
las graves consecuencias de no proteger a los menores de edad de los contenidos de la televisión y de los medios de comunicación: los niños son un grupo de personas que no entienden ciertas cosas como los adultos. Desafortunadamente la inocencia de la niñez se está perdiendo.

Las consecuencias de los medios electrónicos son muy profundas. La línea entre los adultos y los niños empieza a ser peligrosamente delgada. Hay muchas respuestas para ese problema. Muchas de las cuales nosotros no las sabemos. Pero está claro, que si seguimos transmitiendo tanto contenido adulto a los niños, la niñez no podrá sobrevivir. Por definición la adultez significa muchos misterios resueltos y secretos revelados. Si desde el inicio los niños conocen todos los misterios y todos secretos, ¿cómo podemos diferenciarlos de los adultos? (Postman, 1994, pp.84 a 88). Si necesitamos una razón más contundente para el compromiso de la protección del público infantil y juvenil, sin duda la tenemos en la necesidad de evitar la desaparición de la niñez.

\section{BIBLIOGRAFÍA}

DEBRAY, Regis. (1995) El estado seductor, las revoluciones mediológicas del poder, Manantial, Buenos Aires, Argentina.

GIDDENS. Anthony. (2009). Sociology, $6^{\text {th }}$ Ed, Polity Press, Cambridge, UK.

GINNER. S., E. LAMO y C. TORRES. (2002). Diccionario de Sociología. Alianza Editorial S. A. Madrid.

LAKHANI, Dave. (2008). Subliminal persuasion, Influence \& marketing secrets they don't want you know, John Wiley \& Sons, Inc., Hoboken, N.J.

LINDSTROM, Martin. (2008). Buy-ology:Truth and lies about we buy, Doubleday, NewYork.
LINN, Susan. (2004). Consuming Kids. Protecting our children from the onslaught of Marketing \& Advertising, Anchor Books, New York.

MEAD. George. (1999). Espíritu, persona y sociedad. pp. Ediciones Paidós Ibérica S.A, Barcelona.

MURROW, Edward R. (2008). En "Our History Will Be What We Make It", En 50 YEARS OF MURROW, RTNDA, Communicator magazine.

MURROW, Edward R. RTNDA. (1958). Industry Leaders Speech, Chicago Illinois, archivos en audio, RTNDA.

MURROW, RTNDA. (2008). Communicator magazine.

Parents Television Council. (2007). Dying to entertain, Special Report, Los Angeles.

PARSONS, Talcott, BALES Robert f., SHILS Edward A. (1970). Apuntes sobre la teoría de la acción, María Rosa Viganó de Bonacalza (trad.), Amorrortu Editores, Buenos Aires.

PARSONS, Talcott. (2007). El Sistema Social, Editorial Revista de Occidente, Madrid, España.

POSTMAN, Neil. (1994) The Disappearance of Childhood, Vintage Books, New York.

RAPAILLE, Clotaire. (2007). El Código Cultural, Grupo editorial Norma, Bogotá.

RODMAN, George. (2009). Mass media in a changing World, 2. ${ }^{\text {nd }}$ ed., McGraw Hill, New York.

SARTORI, Giovanni. (2005). Homo videns: La sociedad teledirigida, Punto de Lectura, Madrid.

TOFFLER, Alvin. (1991). Power Shift, Bantam Books, New York. 